\title{
EFECTO DEL DEPORTE COMPETITIVO EN EL TEJIDO ESCOLAR DE DOS INSTITUCIONES DE LA COMUNA 16 EN MEDELLÍN
}

Effect of competitive sport as scholar framework of two institutions in the $16^{\text {th }}$ commune of Medellín

Efeito do esporte competitivo no tecido escolar em duas instituições da comuna 16 em Medellín

\section{Álvaro Alexander Mejía Henao}

Universidad de Antioquia, Colombia. Fono: + 5743103522511. Correo electrónico: aamhen@ hotmail.com

\section{Resumen}

En los planes educativos de desarrollo y las políticas de contención social en Colombia (jóvenes, género, integración social, paz y convivencia) el deporte de competencia ha ganado el estatuto de moderador social, quien a la vez en el contexto escolar no escapa a tal pretensión. Esta investigación consideró el deporte de competencia desarrollado en dos instituciones educativas (IE) de la comuna 16 en Medellín, y la creencia social y educativa del deporte como medio generador de cambios en el tejido social. En este estudio se develó que el deporte de competencia escolar esta permeado por el contexto externo, promueve aspectos positivos $\mathrm{y}$ negativos, y posee diferentes significaciones para directivos, profesores, estudiantes y familiares; quienes fueron las voces que soportaron los resultados en este estudio de tipo cualitativo.

Palabras clave: deporte; deporte de competencia escolar; tejido escolar.

\section{Abstract}

In the development educational plans and the politics of social contention in Colombia (Youths, gender, social integration, peace and coexistence), the competitive sport has gained the roll of social moderator, who at the same time in the scholar context does not scape of this pretension. This research was focused on the competitive sport carried out in two elementary and high schools in the 16th commune of Medellin, and from the social and educational belief of sport as a driver of change in the social fabric. This study revealed that 
school sports competition is permeated by the external environment, promotes positive and negative aspects, and has different meanings for managers, teachers, students and families; who they were voice that supported the results in this qualitative approach.

Key words: sport; school sport competition; scholar framwork.

\section{Resumo}

Em os planos educativos de desenvolvimento e as políticas de contenção social na Colômbia, (jovens, gênero, integração social, paz e convivência) o esporte de competição tem ganhado o estatuto de mediador social, quem a sua vez no contexto escolar não se fuga a tal pretensão. Este pesquisa considerou o esporte de competência desenvolvido em duas instituições educativas da comuna 16 em Medellín, e a crença social e educativa do esporte como médio gerador de mudanças no tecido social. Nesta pesquisa apresenta que o esporte de competência escolar está se inserindo pelo contexto externo, promovendo aspectos positivos e negativos, e tem diferentes significações para os gerentes, professores, estudantes e para as famílias; a que eram as vozes que apoiaram os resultados deste estudo qualitativo.

Palavras chave: esporte; esporte de competência escolar; tecido escolar.

\section{Introducción}

El deporte es considerado un fenómeno social, el cual ha sido empleado como medio para responder a ciertas necesidades de cada época: en representación del poder de una nación; para la convivencia con el deporte para paz, la educación, la formación ciudadana y la integración de los sujetos a la comunidad; como espectáculo, visible en el deporte de élite y profesional; para mejorar la salud, para el ocio y la recreación. Estas prácticas deportivas movilizan a las masas, las cuales se configuran por sujetos procedentes de diferentes sectores de la ciudad o diferentes barrios, quienes con su diversidad cultural, económica, de edad, género y sexo, se exponen a un choque e interacción en un escenario competitivo, condición que puede influir sobre el comportamiento de los sujetos, haciendo suponer un efecto en el tejido social. 
El gobierno Colombiano en su retórica ha considerado el deporte como un medio para contribuir a la salud física y mental; como generador de lecciones para la vida basadas en el respeto, la convivencia, el liderazgo y la cooperación; y como derecho social que junto a la recreación son claves para mejorar las relaciones sociales y la convivencia. También, para promover igualdad y ayudar a superar las problemáticas sociales.

En ese sentido (Cayrols y Vitoriano, 2012), (Hoyos et al. 2012), (Gaviria et al. 2012), (Giménez et al. 2010), (Gil et al. 2009), (Llamas y Suárez, 2004), (Arija, 2004) y (Sánchez y Granados 2002), asocian el deporte con aspectos educativos, formativos y en pro de la convivencia. (Camino, et al. 2008), (Socias, 2011), (Santos y Balibrea, 2004) y (Maldonado, 1997) lo referencian como un medio para la integración social.

En ley 1620 de 2013, artículo 25: se compromete al Ministerio de Cultura de Colombia en el marco del sistema nacional de convivencia escolar, a promover estrategias que mediante el arte, la recreación, la cultura y el deporte, aporten a la prevención y mitigación de situaciones de violencia escolar y a la cualificación del uso de tiempo libre de los niños, niñas y adolescentes y a la formulación de iniciativas de convivencia y cultura ciudadana. En esta normativa el deporte aparece como una ruta para la convivencia, pero lo contrario expresan las voces de los actores educativos, jefes de núcleo, rectores, educadores, padres de familia e incluso estudiantes, quienes ponen en tela de juicio los alcances del deporte de competencia escolar.

Medellín en medio de su desarrollo urbano y los dramas sociales que ello trae, considera desde su equipo de gobierno, en los marcos y lineamientos educativos, que la escuela funciona como un lugar de primera línea para favorecer la convivencia y la educación para la convivencia; lo que va en sintonía con lo propuesto por (Ruiz, 2006) que considera la escuela como un territorio facilitador de cambio en un espacio socializado y culturalizado, desde la experiencia y los contextos históricos.

La ciudad también adoptó la semana de la convivencia en el mes de Octubre de cada año, en ese marco actúan los subsistemas de educación, cultura ciudadana, juventud e INDER; hay un tiempo para "las actividades de deporte y convivencia" pero la convivencia no 
aparece como parte de lo curricular, el evento es espectáculo y aun no se ha impregnado en la cultura escolar.

Por su parte la escuela dice reconocer el deporte como un aliado estratégico, para la educación de una formación individual, con más oportunidades y con efectos positivos en lo social, dígase: crecimiento, desarrollo y convivencia. Apuesta por el fortalecimiento del desarrollo personal, social e institucional, que a su vez sirve como instrumento para garantizar la gobernabilidad. Esta concepción positiva de la relación escuela, deporte y convivencia, parece hegemónica en el contexto educativo. El deporte está institucionalizado como un instrumento para educar el cuerpo del estudiantado de manera diferente; práctica que en su escolarización podría contener un potencial transformador para la sociedad.

Ahora, pensar el deporte de competencia y la convivencia escolar y social, implica concebir el deporte como un dispositivo que no se reduce a lo intra escolar, toca toda la ciudad. Por lo que resulta conveniente considerar el contexto en el que están inmersos los escolares deportistas, quienes no pueden desprenderse de las influencias externas al llegar a la escuela. Así lo plantea (Trilla, 1995) quién considera la escuela un lugar cercado por muros porosos, los cuales permiten una interacción constante de doble vía con el mundo exterior.

A propósito y según la defensoría del pueblo de la ciudad (Defensoría delegada para la prevención de riesgo de violaciones de DDHH y DIH, 2013) algunas comunas, entre ellas la 16, lugar donde se desarrolló la investigación, presentan factores dramáticos que dan cuenta de la vulnerabilidad de los niños, niñas y adolescentes, jóvenes, mujeres, población desplazada, docentes, estudiantes y personal administrativo de las instituciones escolares y otros actores de la comunidad. Expuestos a presiones de reclutamiento y utilización para actividades ilícitas, homicidios, explotación y abuso sexual de menores y mujeres, actos de terror, amenazas y restricciones para la movilidad, por parte de los grupos ilegales que operan en la ciudad.

Pero no solo esas circunstancias sociales se deben considerar como influencias que pueden estar modificando las actitudes de los estudiantes, también a través de los medios de comunicación los escolares tienen contacto con la movilización del deporte profesional, el fanatismo, las rivalidades extremas, la violencia entre seguidores y algunas veces entre 
jugadores. En el contexto local, jóvenes hinchas, fueron llevados a la cárcel, acusados de asesinar a un hincha del equipo rival. En la plazoleta de la Institución Educativa Antonio Derka, un colegio de calidad, es asesinado un joven por hinchas del equipo rival. Acciones que dan cuenta de situaciones complejas alrededor del deporte, y dan píe para dudar de lo positivo del deporte competitivo en la escuela.

Esto incita a pensar que algo pasa afuera de la escuela con los jóvenes, en las relaciones que hay entre la gente que habita la ciudad. Y emergen preguntas ¿Cómo se refleja en la escuela este drama social externo del deporte? ¿Qué relación tiene lo que se hace en la escuela, desde lo educativo con ese drama de ciudad? ¿Qué pasa con el deporte de competencia escolar en conexión con esta realidad? ¿La práctica deportiva escolar se matiza y se reproduce condicionada por su orientación y las condiciones sociales de los sujetos?

Hasta este punto parece que el deporte en la escuela tiene un objetivo claro desde lo teórico, lo normativo y lo institucional, pero existe una brecha entre el discurso oficial y el cotidiano escolar, pues el deporte de competencia escolar no escapa a las tramas de agresión y violencia que se vive en las IE. Situación alertada por (Fraile y Diego, 2006) quienes determinan que el deporte puede influir negativamente en los valores educativos como la cooperación y la ayuda entre iguales. (Santos, 2011) por su parte, referencia la práctica deportiva como un espacio donde se presentan conductas de individualismo, trampa, racismo. Las desigualdades y discriminación, con predominio de intereses económicos y publicitarios, la puesta en peligro de la salud como el dopaje y los desórdenes alimenticios.

Todo lo anterior incita a observar el deporte de competencia escolar desde varios focos y acercarse a comprender su efecto sobre la población escolar, pues es posible que estas acciones tengan una influencia en la conducta de los participantes y modifiquen la estructura del tejido escolar.

\section{El deporte para la sociedad}

El deporte como fenómeno mundial es una práctica estrechamente vinculada a la realidad social y cultural. "Las manifestaciones deportivas se consideran como un producto de la 
sociedad o de sociedades que las crean o en las que se desarrollan y, por lo tanto, están dentro de sistemas socioculturales concretos desde los cuales vienen pautadas las características que las conforman.”(cit. en Maldonado, 1997: 10).

Desde diferentes autores es posible identificar como el deporte actúa a veces como generador de conflictos y otras como mediador de tensiones. Su plasticidad le permite funcionar para la prevención de las enfermedades cardiovasculares, el estrés, el sedentarismo, los daños que sufre el equilibrio psicofísico de los sujetos, o como lo plantea (Maldonado, 1997) una actividad compensatoria de las tensiones emocionales producidas por el exceso de trabajo en una sociedad competitiva. (Llamas y Suárez, 2004), (Gaviria y Arboleda, 2009) lo consideran favorecedor de valores, en especial la convivencia. Para (Santos y Balibrea, 2004), como un medio hacia la integración social de la mujer y la lucha contra la discriminación racial y la inmigración. Y según (Elias y Dunning, 1996) puede actuar como un agente de contención y modelación de la conducta de los sujetos. Pero además se reconoce que hay

un opuesto que enturbia el ideal deportivo: al esfuerzo colectivo y al compañerismo se le opone el individualismo, tan presente en el terreno deportivo; al respeto a las reglas, la trampa y la picaresca; a la aceptación de las diferencias, el racismo y la discriminación, que están al orden del día entre deportistas y público; a la lógica amateur, gratuita y voluntaria, se le opone la presencia de los intereses económicos y de la industria publicitaria; a la dimensión saludable, la puesta en peligro de la propia salud con el dopaje o los desórdenes alimentarios; y para concluir la serie, a la idea de que el deporte nos hace iguales se le opone la evidencia de las gigantescas desigualdades que se mueven en su entorno. (Santos, 2011: $58)$.

\section{El deporte para la escuela}

Con la sociedad en constante reconfiguración emergen objetivos y directrices que recaen sobre el sector educativo tocando las escuelas, las que se han convertido en un lugar para el adiestramiento y la modelación del cuerpo, a través de programas con influencias militares, 
religiosas, deportivas, artísticas y recreativas entre otras. El deporte de competencia en la escuela esta estrechamente ligado con el área de educación física, la cual en el contexto educativo Colombiano se ha empleado como medio para la preparación de deportistas de calidad, actividad complementaria de lo intelectual, aglutinadora de la escuela y promotora de espectáculos, actividades de interacción con el ambiente, preventiva contra el alcoholismo y la drogadicción, y controladora y orientadora de deseos ${ }^{1}$.

La educación física además adquiere un compromiso educativo y social por las características de interacción que generan sus clases. (Gómez, 2009) al respecto, plantea la existencia de un compromiso deportivo hegemónico que define la educación corporal a través de la Educación Física, encontrando en este un instrumento de promoción y proyección social, económica y cultural insuperable.

\section{Deporte de competencia escolar}

El deporte se puede movilizar en ámbitos competitivos, lo profesional y lo élite; educativos, de ocio, salud y recreación (Oliva, 1994). En Colombia, Ley del deporte de 1995, artículo 15: considera el deporte en general como una actividad lúdica y de afán competitivo, de comprobación o desafío expresada mediante el ejercicio corporal y mental, dentro de disciplinas y normas preestablecidas orientadas a generar valores morales, cívicos y sociales. (Hernández, 1994) y (Parlebas, 2001) determinan que deporte es aquella actividad que posee tres criterios: Una situación motriz, una competición reglada y la institucionalización.

Hay quienes el concepto de deporte lo expresan por la influencia que trasciende al resultado. (Arija, 2004) afirma que el deporte escolar no es más que un medio donde lo que importa es la educación. (Cobo, 2012) plantean el calificativo de escolar, respondiendo a la condición del deportista como un alumno de la escuela. Para (Blázquez y Amador, 1995) deporte es toda actividad físico deportiva realizada por niños y jóvenes en edad escolar, dentro y fuera del centro escolar, considerándolo incluso como sinónimo de deporte en edad escolar.

\footnotetext{
${ }^{1}$ Ver lineamientos curriculares Educación Física, Recreación y Deporte. Ministerio de Educación nacional, Colombia. Evolución Histórica de la Educación Física Escolar.
} 
Para esta investigación deporte de competencia son las prácticas corporales competitivas desarrolladas bajo un sistema de campeonato reglado, promovidas exclusivamente por la institución educativa, donde los escolares tienen la posibilidad de participar.

\section{El deporte y el tejido escolar}

En lo artesanal el tejido se construye tras la unión de varios hilos, en esta investigación, los sujetos; que con diferentes técnicas forman diversos tejidos, la tela, que homologa la diversidad de la estructura social. (Deleuze y Guattari, 2004) desde el concepto rizoma, proponen que en las relaciones humanas se generan conexiones desde cualquier punto con otro, sin ser necesariamente de la misma naturaleza, estableciendo eslabones diversos: biológicos, culturales, políticos y económicos.

(Gil et al. 2009) plantean una relación entre cuerpo y entorno, donde surgen diferentes formas de interacción entre los sujetos, lo que determina la configuración sociocultural y la constitución del tejido social. Para (Fajardo, 2005), (Castro y Gachón, 2001) el tejido social implica el desarrollo de una sociedad madura y autónoma, que propone y defiende las causas sustentadas en el bien común, afirmando la participación y el empoderamiento ciudadano, la organización y la articulación, la democracia, la cultura y el capital social. (Camino et al. 2008) plantean que en la configuración de redes sociales se puede presentar una influencia en doble sentido; de la red influenciado al sujeto o por el contrario del sujeto a la red.

Siendo los sujetos la unidad estructurante del tejido escolar, son quienes desde su diversidad la caracterizan. (Bourdieu, 1997) considera que cada sujeto desde las interacciones establecidas con su núcleo familiar y con la sociedad, va acumulando con el tiempo una serie de características, capital cultural, que le aportan conocimiento, educación, habilidades y ventajas, dotándolo de un estatus, lo que le concede un espacio dentro de la sociedad. Es por eso que en este contexto se considera el tejido escolar como un espacio social de interacción entre los sujetos, estructurado por reglas, normas formales, institucionales e informales, sociales, donde cada uno desde arraigo cultural y su nivel de participación pueden conformar una nueva red escolar o adherirse a alguna existente. 


\section{Metodología}

La comuna 16 de Medellín conformada por 21barrios, es la de mayor densidad poblacional y se considera una zona de potencial económico, cultural y social con incidencia para toda la ciudad ${ }^{2}$. Es una de las de mayor inversión en infraestructura deportiva, especialmente para los Juegos Suramericanos del 2010, escenarios públicos que según la alcaldía de Medellín, se prestan para la integración y socialización de la ciudad. La comuna posee 68 IE entre privadas y públicas, que están bajo la administración de los núcleos educativos 934 y 935. El núcleo 935 cuenta con 37 IE de las cuales 7 son oficiales, 10 privadas y 20 dedicadas a la atención de la primera infancia, de allí se profundizaría en el deportivo de competencia escolar, sólo en dos IE, las cuales presentan condiciones diferentes, lo que no posibilita compararlas, pero sí identificar su desarrollo bajo sus condiciones.

Las dos instituciones, una pública y otra privada, fueron seleccionadas por: uno) La ubicación geográfica que permite hablar de lo heterogeneidad de la comuna, reflejada en las instituciones; dos) presentan diferencias desde el orden económico, lo público y lo privado; tres) una de ellas se ubica en área conflictiva marcada por la violencia, Belén Rincón y la otra en un lugar donde el conflicto es en menor expresión; cuatro) una de ellas no difiere significativamente en su estructura y organización deportiva de las demás de su orden, la pública, centrando su actividad deportiva en juegos intramurales, y la otra se refleja como un lugar emblemático en el deporte competitivo escolar, en competiciones internas y externas.

El estudio sugirió una investigación cualitativa, etnográfica. (Hammersley y Atkinson, 1994) y (Rockwell, 2009) la consideran una forma de participación en la vida cotidiana de las personas de una comunidad durante un periodo de tiempo. Profundización que permite pensar en el desarrollo de la práctica deportiva y establecer un registro que represente toda su actividad, así como lo plantea (Rockwell, 2009) quien establece la importancia de documentar lo no documentado.

Se logró un acercamiento a la cultura escolar, un contacto vivencial a su realidad deportiva, a las reglas del juego, las leyes, disciplinas deportivas, las emociones de los participantes,

\footnotetext{
${ }^{2}$ Plan de desarrollo local fase II. Belén - Comuna 16 2004-2011.
} 
sus sentidos y significados. Los informantes clave fueron contactados por la referencia del profesor conocedor de las prácticas deportivas de la institución; y por la presencia del investigador en medio de la actividad deportiva, en los escenarios deportivos, conversando con jugadores, espectadores y acompañantes.

La recolección de la información se hizo durante el 2014 y 2015 a través de: observaciones y registros de campo, desplegadas en diferentes horarios y momentos de competencias deportivas; entrevistas a profundidad, individuales y grupales.

7. Los significados y el tejido escolar en voz de los participantes. El deporte de competencia escolar como catalizador positivo

El deporte de competencia por estar situado en un contexto educativo debe contribuir hacia el desarrollo integral de los sujetos, de aptitudes ciudadanas relacionadas con lo social, y de capacidades encaminadas hacia la formación práctica para el trabajo, según los lineamientos curriculares. Dentro de esos objetivos el deporte tiene la capacidad de contribuir a la formación del estudiantado, así lo han hecho saber algunos participantes de las IE donde se desarrolló la investigación, dijo un directivo institucional "Se está utilizando el deporte como un beneficio para la convivencia, para el trabajo en equipo, para fortalecer la formación como individuo”.

Afirmaciones que abundan cuando se pregunta acerca de lo positivo del deporte, pues es la convivencia una referencia frecuente, favorecedora de las relaciones interpersonales, Afirmó un escolar de $9^{\circ}$ "Es una forma de participar, de recrearse y de encuentro con todos los grupos".

(Sánchez y Mosquera, 2011) confirman la utilización del deporte como elemento educativo para salvar de la exclusión y la discriminación por razones de género, edad, raza, religión, etc. Objetivo que se establece de manera intrínseca en los deportes de competencia de estas escuelas, producto del trabajo en equipo o de compartir los gustos por una misma práctica. Comentó un escolar de $9^{\circ}$ “Cuando juega el salón, la mayoría del salón se hacen en las gradas con bombas, pitos. Nos organizamos en el salón, y si perdemos pues también alentamos, lo importante no es ganar". 
Así sucede en el contexto educativo, espacio en el que (Fraile, 2004) considera el deporte como un instrumento poderoso hacia la educación para la convivencia civil. En el intento de la escuela por establecer un modo de convivencia mediado por el deporte, implica que los sujetos se adhieran a unos principios establecidos al enfrentarse a una situación interactiva de cara al juego, construyéndose vínculos entre estudiantes, que hablaron de amistad, unión y compañerismo, acciones que según ellos les hace parecer como una familia dentro del contexto escolar. "Uno se calienta y empieza a chocar duro pero ahí todo se queda, después todos salimos y hacemos la vaca para la gaseosa entre todos, todos somos parceros". Profesores "Antes que una relación de amistad se crea un lazo de amistad y de conocer más al otro". Padres de familia "Es como generar competencia sana entre ellos, el mejor amigo, la mejor persona, más que todo es como conocerse entre ellos mismos"

Ciertos vínculos parecen ser producto del favorecimiento regulador de la conducta promovida por la práctica deportiva, algunos de ellos están sujetos a las reglas del juego y las normas instauradas en la institución. En palabras de (Elias y Dunning, 1996) es autorregulación, el control de las emociones hacia la pacificación, pues el deporte está diseñado para despertar emociones, evocar tensiones en forma de excitación controlada, sin los riesgos presentes en otras situaciones de la vida, puesto que en los deportes los seres humanos luchan entre sí directa o indirectamente, lo más parecido a una batalla. Expresó un escolar $10^{\circ}$ "Lo que pasa en la cancha se tiene que quedar en la cancha"

De aquí que representen un vívido ejemplo de uno de los problemas centrales de numerosos deportes: el de cómo reconciliar entre sí, con base en su diseño, dos funciones contradictorias - de-controlar agradablemente los sentimientos humanos, es decir, evocar a plenitud una emoción placentera por una parte, y conservar sin embargo en vigor una serie de coerciones que mantengan bajo control las emociones de-controladas, por la otra (Elías y Dunning, 1996: 66).

Aportaron algunos escolares de $10^{\circ}$ "En el juego hay muchos que se tiran duro pero después ya a lo último, cuando se acaba el partido ya hacen las paces", "Por ejemplo mira 
esta raya (límite del campo de juego, adentro, afuera) de acá para adentro no tengo amigos, de aqui para a fuera todos somos parceros".

Si bien se pudo identificar que el deporte favorece la conducta, ya sea desde naturaleza del juego o producto de las restricciones que demandan un control de las emociones, a este se le puede adicionar la acción coercitiva que generan los profesores y algunos padres de familia, quienes decretan la participación de los estudiantes en los diferentes deportes como premio o castigo, dependiendo de la conducta en situaciones externas al juego. Dijo un Profesor "Si se va a castigar, use los métodos normales...pero con una cosa que no tiene nada que ver ... lo veo como algo malvado, quitarles algo que les gusta...lo que pasa es que les gusta tanto que es donde más se aprovechan, premio y castigo”; un padre de familia "Si ellos se portan mal se les debe quitar lo que les gusta, que le gusta el fútbol, el deporte, va mal en el colegio o en disciplina, se le quita el fútbol"; un escolar de $10^{\circ}$ "Ahí con lo de la justicia están jodidos, se supone que uno no debe juntar ni el deporte, ni la academia, ni nada, ahí nos tienen que dar la oportunidad”

Decisiones que son reflejo de la existencia de relaciones de poder, en las cuales algunos padres de familia contribuyen a su consolidación aceptando la supresión de la actividad deportiva para los estudiantes. Situación que no es congruente entre el discurso deportivo hacia la formación en valores, y la convivencia que pretenden la educación de los sujetos. (Lazzarato,2000) presenta una idea al hablar de biopolítica, que servirá para entender este suceso en la escuela, se refiere a la existencia de relaciones estratégicas en las cuales siempre existen dos características entre los sujetos, una de obediencia y otra de mando. Lazarrato por su parte plantea que el poder se construye desde la base a partir de mecanismos infinitesimales, los cuales luego serán investidos, colonizados por mecanismos más generales y grandes de dominación. Situación reflejada en la escuela a través del deporte, pues docentes y algunos directivos se aprovechan de su demanda para regular y contener a los estudiantes.

Pareciera entonces que deporte si funciona como un catalizador positivo, sustentado desde los discursos de los participantes y corroborado en las notas de campo producto de las observaciones, existiendo un impacto positivo en las relaciones interpersonales establecidas 
principalmente entre los sujetos participantes, lo que ha de suponer una mejor calidad en el tejido escolar, en la convivencia. (Elias y Dunning, 1996) resaltan que el aprendizaje del autocontrol es un universal humano, una condición común de la humanidad. Sin ella, las personas, como individuos, no lograrían convertirse en seres humanos y, como sociedades, se desintegrarían con rapidez.

\section{El deporte de competencia escolar como catalizador negativo}

En el trascurso de un partido los jugadores experimentan múltiples sensaciones producto de las condiciones de juego, la fase desarrollada, sea clasificatoria o final, por el desempeño individual y grupal, el resultado a favor o en contra; son circunstancias que influencian a los sujetos una carga emocional, posibilitando la alteración de su comportamiento frente a la práctica, con actitudes agresivas producto de la competencia deportiva. La tensión se puede sentir antes, durante y después del juego. Esto se ha visto entre los protagonistas y también entre espectadores, barras y simpatizantes, quienes también hacen parte del evento deportivo.

Con la finalidad de exponer lo hallado en la investigación, se propone imaginar un partido de futbol de salón, para trasladar una presencia simulada, desde lo observado y documentado a través de los diálogos en la escuela, hacia el momento deportivo. Imagine el campo de juego, estudiantes y algunos profesores preparados para jugar, barras o acompañantes y otros profesores que controlan, hasta este punto todos con una posición indefinida frente al partido. Ahora atribúyale un sentido de competencia, la cual busca un ganador al final del partido o del torneo. Piense en la disposición de los cuerpos al inicio del partido, y los dos equipos quieren ganar “como sea”, el calor del juego suscita más tensión, vienen faltas, las decisiones arbitrales causan acuerdos y desacuerdos, las barras empiezan a distraerse y dejan a un lado el apoyo para su equipo, comienzan los cruces de palabras entre varios sujetos que participan en la actividad, se escuchan agresiones verbales y se ven las físicas, algunas sancionadas por el juez, otras pasajeras y otras que trascienden al final del partido hacia contextos diferentes al deportivo, hacia la escuela o fuera de ella.

Se podría pensar que todo esto es producto del juego, momento que se presta para la expresión de rivalidades, agresiones verbales y físicas, comentó un escolar de $10^{\circ}$ "Es que 
siempre va a existir una rivalidad, sea con el equipo que sea, siempre va a existir una rivalidad". Testimonio que puede corroborar que el juego bajo modalidad competitiva, produce tensiones. Pues se identificaron rivalidades transitorias, que surgen de la intensidad del juego y son entendidas como relaciones deportivas, entre jugadores. Comentaron algunos estudiantes

Escolar de $8^{\circ}$ "Los hombres juegan muy animal, muy brusco... Eso hasta pelean... ni se les puede caer, porque ya están ahí casi para pegarse"

Escolares de $11^{\circ}$ "Nosotros jugamos por el orgullo, por el honor", "La verdad hay un caso que pasa en el fútbol, usted me pegó, ya sabe me las debe y cuándo ya sienta el "choque”, y él dice, -jah! ¿Qué pasó?, -jah! usted me las debía de ahorita”.

Por otro lado, se pude decir que las rivalidades también trascienden o ingresan al evento deportivo, en doble dirección entre la escuela y barrio. Dijo un escolar de $9^{\circ}$ "Ellas aprovecharon el partid...para gritarnos cosas a nosotras...pero nosotras no nos dejamos, respondemos... Porque de todas formas nos caen mal, ellas nos llevan la mala, pero nosotras se las llevamos más”

Un escolar 8: “Las mujeres son más rabiosas, se llevan más la mala... porque hay unas que se llevan la mala de los salones, entonces ahí en el partido se desquitan"

Un profesor "Algunos traen su situación personal del contexto donde viven y se traslada a las acciones de las canchas. Qué es lo que hace que de pronto haya gestos violentos, de pronto una frase, una mirada, cosa muy ajena a lo que es realmente al deporte”.

Consecutivamente de la rivalidad presente y las emociones alteradas en los partidos, surgen las agresiones verbales y físicas. Las verbales parecen ser más comunes en el contexto escolar. Dijo un escolar de10 "Honestamente sin pelos en la lengua... hay un roce entre quienes se la llevan casada, pelean por lo general, no siempre, pero si hay cómo rabia entre los dos, sí hay pelea, pero de resto, se rozaron, se enojaron y al ratico se contentaron, o sea, aquí de que se ve, se ve, pero muy pocas veces se va a mayores"

Entre estas manifestaciones de agresión verbal se esconde la discriminación y la exclusión, una manera de agresión simbólica. Relato un escolar de $9^{\circ}$ "Ellas empezaron a gritarle 
cosas a Ana, entonces ella les respondió, y se vino todo ese África a buscar acá, se vino la oscuridad, yo pensé que llegó la noche”

Nota de campo: Escuela está ubicada en la zona sur de la comuna, pertenece a un barrio de estratos con prevalencia 1 y 2 , se desarrolla un partido de interclases entre $8^{\circ}$ y $9^{\circ}$ masculino. Un muro de ladrillos y una malla separan la escuela de las casas del barrio. Durante el partido se reúnen estudiantes jugadores, espectadoras y animadoras. Una profesora y un profesor ven el juego y tienen una función de controlar la disciplina en el descanso. Lo multiétnico se hace presente, "blancos", mestizos y afro descendientes. Las mujeres son quienes hacen barra a algún equipo con porras y bombas. Una de las barras la de mayor número de estudiantes se apodera del centro de la tribuna, entre ellas algunas afro descendientes, que son llamadas "África" por la otra barra ubicada en un extremo de la cancha, separadas por la malla, de un grupo minoritario de mujeres "mestizas". Las barras celebran los goles, animan su equipo y a la vez gritan y lanzan palabras cargadas de sentimientos que parecen provenir de asuntos externos a la escuela. En pleno partido, “África” salta de la tribuna, invade a la cancha y se desplaza hasta la parte posterior de la malla, donde se encuentra el grupo de "mestizas". África frentea a la barra del otro grupo, sin pasar de lo verbal. Ante la situación, la profesora que está cerca a lugar de los hechos interviene indirectamente con su presencia al acercarse al grupo. Se acaba el conflicto. El juego continúa, los goles van y vienen, no hay actos violentos y los jugadores no prestaron atención a la situación entre barras.

Elias y Dunning, (1996) plantearon que en el intento de entender los comportamientos agresivos de hinchas o seguidores en el fútbol, se debe tener en cuenta la condición humana y la forma en que se experimenta, pues hay factores económicos, de reconocimiento e inclusión social, que influyen en el sujeto para que se comporte de tal manera, quien en una expresión grupal modifica su exclusión y la falta de atención, ahora es parte de una multitud, es poderoso.

Por lo que pensar en esas rivalidades de manera aislada, sería desconocer el aporte de (Bourdieu, 1997) cuando habla del capital social, el cual proviene de las redes tejidas a lo largo de la vida desarrollada en diferentes grupos a los que el sujeto pertenece, como la 
escuela o el barrio. Espacios donde el sujeto configura su personalidad y conducta, la cual puede estar sujeta a situaciones conflictivas dentro del barrio. Conflictos que al momento de ingresar al colegio, en medio de las prácticas deportivas parecen continuar, aprovechando las características de la competencia, que plantean un enfrentamiento entre dos equipos, simulando una guerra donde hay un ganador y un perdedor.

Ahora bien, si las emociones provocadas en medio de los juegos competitivos alteran la conducta, fue posible corroborar que hay ocasiones en que esta incita agresiones violentas. Dijo un escolar de $11^{\circ}$ “Juego más que todo micro, pero aquí no, acá llegan es a partirlo a uno, entonces me da miedo. Aquí es más violento", un escolar de $7^{\circ}$ "Hay unas que se meten solo a dar pata...unas son muy bruscas y ya uno juega al nivel de ellas... porque si están cayendo muy cochino uno también les cae", Un profesor "Suspendido el inter clases un mes y medio, después se dieron pata más suave. Eso ha decrecido, pero entre ellos se juega por dominar físicamente al otro... En un juego de inter clases hubo una pelea que involucró estudiantes de diferentes barrios, hubo bonche, puño y pata”

Estas formas de agresión se identifican con un rasgo común, el daño físico, independiente si su origen el juego o una situación externa, son acciones de violencia física que generan malestar y tensión entre estudiantes. Las que provocan además una restricción de participación en algún deporte.

Finalmente estas acciones que involucran rivalidades, que se manifiestan a través de agresiones verbales y físicas, son producto de las relaciones establecidas de manera externa y/o internas al juego, siendo las que caracterizan el deporte de competencia escolar como un catalizador negativo, pues allí se reproducen conflictos de tipo étnico-cultural, intergénero y de dominación a través del triunfalismo en la competencia, lo que sin lugar a dudas representa una alteración en las formas de relación entre los participantes, que son quienes conforman del tejido escolar. Por lo que habrá que pensar en lo advertido por (Arija, 2004) quien enuncia, que si la valoración social de la práctica deportiva corresponde a planteamientos competitivos, selectivos y restringidos, pueden no ser compatibles con las intenciones educativas del currículo escolar.

\section{Conclusiones}


De lo anterior se puede concluir que el deporte escolar de competencia como está concebido en la escuela, influencia el tejido escolar, con acciones que generan convivencia y tensiones en forma de agresión, pues en la planeación de las competencias no se consideran ni la procedencia, ni las condiciones en que llegan los estudiantes al juego, por lo que este en ocasiones se ve permeado por un contexto externo.

Es claro que el deporte escolar en las IE es orientado y se presume de él una formación ciudadana y en valores desde lo retórico, pero los resultados de la práctica muestran ambivalencias entre aspectos positivos y negativos. Pero este reconocimiento como medio educativo que recibe el deporte de competencia, se ve también deslegitimado cuando se castiga a los estudiantes con la no participación deportiva, ya sea por una razón académica o por un incidente disciplinar durante la jornada escolar.

Es así como se puede afirmar que el deporte de competencia por sí solo no es una herramienta que contribuya a la educación, que si bien tiene la posibilidad de crear lazos de amistad especialmente al interior de un grupo, también suscitan tensiones, producto de la competencia, la cual en pocas ocasiones trascienden el juego.

Al final estos beneficios formativos para el sujeto con la práctica deportiva, no se han incluido de manera consienten en los escolares, pues no se evidencia un proceso de sensibilización para que los estudiantes se enteren del verdadero objetivo con estos eventos deportivo en la institución.

\section{Implicaciones}

El ánimo de esta investigación fue reflexionar sobre la actividad deportiva escolar y si es el caso, de una manera muy respetable favorecer la reestructuración de estas prácticas, para disminuir la brecha presentada entre el discurso y la realidad.

Para ello es pertinente que en la planeación de las actividades deportivas se piense en las necesidades educativas de los estudiantes, lo que implicaría restructurar el evento en función de la convivencia escolar, pues se viene desarrollando bajo un modelo competitivo imitando a la élite deportiva. Una posibilidad es modificar la orientación de competencia, 
por una de recreación y de participación que pueda incluir a más actores escolares sin importar su habilidad en el deporte.

Se deben idear acciones orientadoras y educativas para que los escolares continúen inmersos en la actividad deportiva, pues si se dice que el deporte es un medio educativo y parte del currículo, no se debe castigar al estudiante excluyéndolo de participar. El deporte no debe ser un mecanismo de control de la disciplina y de lo académico utilizado por los profesores.

Por ultimo entre directivos y profesores institucionales, especialmente los de educación física, se deben estructurar sesiones periódicas de control, para la reflexión no solo sobre el fenómeno deportivo, sino también sobre las demás áreas escolares, acción que contribuirá a identificar la coherencia entre el objetivo, la metodología y los resultados, previamente planeados.

\section{Referencias bibliográficas}

Arija, A. (2004). Deporte y educación. Revista de Educación, 335, 45-60.

Blázquez, D. y Amador, F. (1995). La iniciación deportiva y el deporte escolar. Barcelona: Inde.

Bourdieu, P. (1997). Capital cultural, escuela y espacio social. Mexico: Siglo XXI.

Camino, X. Gutiérrez, G. M., y Barata, N. (2008). Redes sociales y deporte en los espacios públicos de Barcelona. Apunts: Educación Física Y Deportes, 91, 12-28.

Castro, A. y Gachón, A. (2001). Tejido social y construcción de sociedad. ONG Cordillera. Centro de Estudios Municipales.

Cayrols, R. y Vitoriano, J. (2012). Práctica deportiva, convivencia intercultural y ciudadanía: Integración socio-educativa a través del Judo. Anduli: Revista Andaluza de Ciencias Sociales, 11, 87-100.

Cobo, C. (2012). El deporte escolar: un análisis crítico a través de cuatro historias de vida deportiva. 
Defensoría del pueblo. Defensoría delegada para la prevención de riesgo de violaciones de DDHH y DIH. (2013). (No. 008-13). Colombia.

Deleuze, G. y Guattari, P. (2004). Mil mesetas. Valencia: Pre-textos.

Elias, N. y Dunning, E. (1996). Deporte y ocio en el proceso de la civilización. Madrid: Fondo de Cultura Económica.

Fajardo, J. (2005). Construcción del tejido social y la convivencia ciudadana. Revista Debates, 41, 17-78.

Fraile, A. (2004). Hacia un deporte escolar educativo. In El deporte escolar en el siglo xxi: analisis y debate desde una perspectiva europea: 9-28.

Fraile, A. y De Diego, R. (2006). Motivaciones de los escolares europeos para la práctica del deporte escolar. Revista internacional de sociología: 44, 86-109.

Gaviria, C. Chaverra, B, Arboleda,V. Vargas, Andrés, y Cano, J. (2012). Deporte extraescolar para la convivencia. El caso de las escuelas populares del deporte, Medellín-Colombia. In IV Congreso Internacional de Ciencias del Deporte y la Educación Física. (VIII Seminario Nacional de Nutrición, Medicina y Rendimiento Deportivo). España.

Gil, E. Cuervo, G. López, P. Figueroa, G., Tobón, Á. y Posada, C. (2009). Las expresiones motrices como alternativa para la reconstrucción del tejido social. "Experiencia evaluativa de la intervención social en la Escuela de Iniciación y Formación Deportiva Santo Domingo Savio.” Educación Física Y Deporte: 22, 1, 73-83.

Giménez, J. Abad, M. y Robles, J. (2010). La enseñanza de deporte desde la perspectiva educativa. Revista wanceulen e.f. digital: 5, 90-103. Consulta realizada el 13 Mayo de 2015. http://rabida.uhu.es/dspace/handle/10272/3316

Gómez, W. (2009). El cuerpo en la escuela: los dispositivos de la sujetación. Aproximaciones Epistemológicas Y Pedagógicas a La Educación Física. Un Campo En Construcción: 9, 1, 159-179. 
Hammersley, M., \& Atkinson, P. (1994). Etnografía: métodos de investigación. España: Paidós.

Hernández, J. (1994). Análisis de las estructuras del juego deportivo. España: Inde

Hoyos, C. García, C. y Pueyo, Á. (2012). Caracterización de los programas de deporte escolar en Bogotá. Educación Física Y Deporte: 31, 1,853-860.

Lazzarato, M. (2000). Del biopoder a la biopolítica. Revista Multitudes. Consulta realizada el 13 Mayo de 2015. http://ecaths1.s3.amazonaws.com/etica/58981039.DEL\%20BIOPODER\%20A\%20 LA\%20BIOPOL\%C3\%8DTICA\%20(Lazzaratto).pdf

Ley del deporte, Colombia Pub. L. No. 181 de 1995 (1995).

Llamas, G. y Suárez, D. (2004). Los valores en el deporte. Revista de Educación: 335, 919.

Maldonado, M. (1997). Los efectos sociales del deporte: ocio, integración, socialización, violencia y educación.

Oliva, C. (1994). La enseñanza del deporte en la educación obligatoria: enfoque metodológico: Revista Complutense de Educación, 5, 2, 137-152.

Parlebas, P. (2001). Léxico de praxiología motriz. España: Paidotribo.

Rockwell, E. (2009). La experiencia etnográfica: historia y cultura en los procesos educativos. España: Paidós SAICF.

Sánchez, M. y Granados, S. (2002). Deporte para la guerra, versus deporte para la paz: reflexiones sobre el carácter educativo del deporte. Revista Electrónica Interuniversitaria de Formación Del Profesorado: 5.

Sánchez, P. y Mosquera, G. (2011). Tratado sobre violencia y deporte. Sevilla: Wanceulen Editorial Deportiva.

Santos, A. (2011). Exclusión social y deporte. Metrópolis: 81, 57-59. 
Santos Ortega, A. y Balibrea M.. (2004). Deporte, mujer y exclusión social. Experiencias europeas de inserción a través del deporte.

Socias, A. (2011). L'activitat física i l'esport com a mitjà d'integració social i transmissió de valors a joves socialment desfavorits. In Investigació I Innovació Educativa I Socioeducativa: 2, 2, 19-38.

Trilla, J. B. (1995). La escuela y el medio: Una reconsideración sobre el contorno de la institución escolar. Volver a pensar la educación: 217-231. 